\title{
PRELÚDIOS DE UM CONSTITUCIONALISMO POPULAR E LATINO- AMERICANO NO BRASIL? PARTICIPAÇ̃̃̃O DEMOCRÁTICA PÓS-88 E QUEDA DO DECRETO LEI 8.243/2014
}

\author{
PRELUDES OF A POPULAR AND LATIN-AMERICAN \\ CONSTITUTIONALISM IN BRAZIL? DEMOCRATIC PARTICIPATION POS- \\ 1988 AND THE OVERTURN OF THE EXECUTIVE ORDER N ${ }^{\circ}$ 8.243/2014.
}

\author{
Maria Helena Fonseca Faller** \\ Katya Kozicki***
}

\begin{abstract}
Resumo: Este artigo pretende avaliar a proposta do constitucionalismo latino-americano e do constitucionalismo popular como possibilidade de se repensar as democracias constitucionais contemporâneas, fundamentadas na presença da cidadania na definição da política e da Constituição. A partir disso, analisa em que medida a democracia brasileira pós- 88 obteve resultados positivos no que se refere a participação popular na vida política e na construção dos direitos constitucionais, verificando qual contexto permitiu a derrubada do Decreto-Lei 8.243/2014. Identifica, por fim, os limites institucionais existentes à participação do cidadão na política, sem deixar de perceber prelúdios de uma potencialidade democrática ainda a ser experimentada.

Palavras-chave: Constitucionalismo latino-americano; constitucionalismo popular; Constituição Federal de 1988; Decreto-Lei 8.243/2014; democracia constitucional.
\end{abstract}

Abstract: This article intends to evaluate the Latin-American and Popular constitutionalism proposals as possible ways to rethink contemporary forms of constitutional democracy based on the fundamental principle of citizen participation in the construction of Politics and Constitutional laws. From this, it analyses the extent to which the Brazilian democracy pos-1988 generated positive outcomes in terms of popular participation in its political life and in the establishment of constitutional rights, considering the context that led to the overturn of the Executive order n. 8,243/2014. At last, it identifies existing institutional limitations to citizen participation in politics, while considering the preludes of a democratic potential yet to be experienced.

Key-words: Latin-American constitutionalism; popular constitutionalism; constitutional democracy; Executive order nº 8.243/2014; Federal Constitution of 1988.

\footnotetext{
* Esse artigo foi produzido no âmbito do projeto de pesquisa intitulado: "A identidade dos sujeitos constitucionais na América Latina e no Brasil: entre o constitucionalismo popular e o constitucionalismo democrático", financiado pelo CNPQ.

** Doutoranda do Programa de Pós-Graduação em Direito da Pontifícia Universidade Católica do Paraná, professora licenciada da escola de Direito da UNIBRASIL, presidente da Associação Nacional por uma Economia de Comunhão no Brasil. E-mail: mhfaller@outlook.com

*** Professora titular da Pontifícia Universidade Católica do Paraná e professora associada III da Universidade Federal do Paraná, programas de graduação, mestrado e doutorado em Direito. Bolsista de produtividade em pesquisa do CNPQ. E-mail: kkozicki@uol.com.br.
} 


\section{CONSIDERAÇÕES INICIAIS}

A reflexão em torno do debate entre constitucionalismo e democracia encontra-se com vigor total nestes tempos. A pergunta clássica, colocada pela teoria constitucional há décadas, ainda causa desconforto e controvérsia: a quem cabe interpretar e atribuir significado ao texto constitucional? A resposta pode parecer quase óbvia, porém, as implicações que essa resposta gera exigem pensar a Constituição e a política por novas perspectivas, bastante desafiadoras.

O povo mítico, consagrado nos textos constitucionais dos primórdios do constitucionalismo como titular do poder constituinte, requer do pensamento políticoconstitucional de hoje um modo revigorado de compreensão do seu papel justificador da constituição. Se é o povo quem constitui a constituição, seu poder constituinte deve perpassar os momentos fundacionais ou de ruptura institucional, de política extraordinária, para tornar-se o elemento estabilizador ou desestabilizador da ordem constitucional (por que não?), questionando-a e exigindo uma vigília constante do sentido atual dos direitos e da justiça, levando-a constantemente a pergunta original: qual drama essa constituição pretendeu e pretende resolver? ${ }^{1}$

O elemento desestabilizador deve ser visto com olhar positivo, como parte indissociável de um regime que se pretende democrático e constitucional. Desestabilizar o estabilizado significa questionar o status quo, quando este se torna um elemento de justificação do enfraquecimento democrático. A desestabilização aqui proposta parte de uma constante interpretação do conteúdo dos próprios direitos fundamentais e da constituição compreendida como o pacto político fundamental que funda a democracia constitucional.

A compreensão de democracia constitucional que fundamenta essa analise se constrói a partir da recuperação do papel do poder constituinte na construção do Estado de Direito. Ou seja: retira o povo de seu papel de mito justificador, para alça-lo ao papel de protagonista na construção do sentido da constituição e da democracia.

Essa concepção exige pensar a ideia de democracia e do constitucionalismo fundamentadas na igualdade, encaminhando-a para o agir concreto. Igualdade no sentido de que todas as pessoas possuem a mesma dignidade moral e são iguais em suas capacidades mais básicas. A ideia de que existem pessoas, dentro do sistema democrático, que têm status superior em relação às demais, por qualquer razão que seja, é injustificável. 
Prelúdios de um constitucionalismo popular e latino-americano no Brasil? participação democrática pós-88 e queda do Decreto-lei 8.243/2014

Todos os indivíduos possuem igual direito de intervir nos assuntos que afetam a sua comunidade e merecem participar do processo decisório em pé de igualdade, entendida como igual consideração e respeito por cada um (DWORKIN, 2011, p. I - XVIII).

O que esse agir concreto implica? Pensar a democracia constitucional constituída por um espaço de deliberação coletiva, construída a partir dos sujeitos que serão diretamente afetados pelas decisões, que se colocam juntos para dialogar e realizar o valioso esforço de reconhecer e entender o ponto de vista dos demais. Esse exercício reforça a capacidade de uma comunidade de tomar as melhores e mais imparciais decisões, efetivamente democráticas, coletivas e valiosas (GARGARELLA, 2015, p. 2000-2010).

O constitucionalismo popular ${ }^{2}$ tem se apropriado dessa reflexão com grande vigor, ao propor que se repense a restauração do povo como principal interprete da constituição (não o único), envolvendo-o no debate institucional com soberania de decisão e deliberação. Não retira a importância da função democrática e contra majoritária das cortes, tampouco, enfraquece ou desvaloriza o debate sobre a necessidade de maior empoderamento do Poder Legislativo, face aos efeitos negativos da judicialização da política. Sua proposta propõe um ir mais além: pensar a democracia e o constitucionalismo para além do debate judicial review e poder legislativo (política adstrita a esfera estatal). Isso porque as democracias representativas expressam sinais de crise e de certo esgotamento pela distância concreta verificada entre representantes e representados, que aprisiona a política aos espaços estatais.

Para isso é necessário repensar os desenhos institucionais de nossas estruturas públicas e suas interações com as esferas e instituições privadas, de modo que permitam que esses processos de construção das políticas se deem com participação real da cidadania diretamente envolvida nessas questões. Ainda, requer admitir que a construção da constituição não está adstrita aos tribunais constitucionais ou ainda ao poder das legislaturas que representam o povo, mas ao povo propriamente dito, em suas mais variadas formas de organização e participação cidadã. Exige pensar a relação entre o direito e a política de modo fluido, retirando o monopólio da "última palavra" sobre o que é direito da institucionalidade estatal. Coloca a constituição no seu devido lugar, no seio da política, sem negociar o inegociável - a democracia e os direitos fundamentais, exigindo a coragem de protagonizar, em certo modo, o que se chama de experimentalismo democrático. 
Nessa perspectiva, o constitucionalismo latino-americano expressa algumas conquistas, alguns esforços concretos traduzidos nos novos pactos constitucionais celebrados na região. Trata-se de um processo bastante conflituoso, repleto de recuos e avanços, que traduzem um esforço de recuperar o papel fundacional do poder constituinte, tornando-o ativo e constante na produção do sentido da constituição.

A América Latina é expressão viva da complexidade, da desigualdade, das violações cotidianas de direitos fundamentais, da normalização do estado de exceção. Cenário profícuo para tentativas de instauração de democracias constitucionais que trazem a nu, constantemente, a tensão entre política e direito, entre democracia e constitucionalismo.

É neste cenário que se instaurou o processo de democratização do Brasil, que após uma ditadura violenta, pretendeu dar a si uma Constituição chamada de cidadã, democrática, rica e densa em direitos e contradições, uma vez que, ao lado de um amplo rol de direitos e garantias, abrigou um sistema de organização de poderes bastante hostil a concretização de suas principais promessas.

Não obstante os retrocessos e obstáculos, é visível que o cenário político pós88 permitiu uma maior participação da cidadania na política, institucionalizada através de vários instrumentos aptos a dar voz ao povo. Porém, ainda se constata vários entraves institucionais, significativos e simbólicos do longo caminho que separa o ideal expresso pelo poder constituinte de uma democracia constitucional e sua concretização.

A derrubada do Decreto-lei 8.243-2014 é um fato que simboliza a resistência, as incompreensões, os conflitos e o temor das instituições e dos diversos focos de poder distribuídos na sociedade, do que pode significar um governo efetivamente democrático, nos termos em que propõem o constitucionalismo popular e o novo constitucionalismo latino-americano. Há ainda um mito em torno da ideia de democracia, aliada a uma compreensão estreita de maiorias desorganizadas e apaixonadas, que remonta aos eventos dos regimes totalitários do século XX.

Nesse sentido, este trabalho propõe-se a verificar em que medida a democracia brasileira pós- 88 obteve avanços concretos no que se refere a participação popular na construção da política, considerando os limites institucionais que se tornaram evidentes com a derrubada do Decreto-Lei 8.243/2014. O fio condutor adotado para essa análise será o diálogo entre as propostas do constitucionalismo e constitucionalismo popular, como possibilidade de se repensar as democracias constitucionais dos dias de hoje. 
Prelúdios de um constitucionalismo popular e latino-americano no Brasil? participação democrática pós-88 e queda do Decreto-lei 8.243/2014

Parte-se da hipótese que não obstante os limites institucionais existentes à participação da cidadania na política no Brasil, é possível perceber alguns avanços importantes a partir de instrumentos democráticos em curso e ainda, uma forte potencialidade democrática ainda a ser experimentada, mesmo que se admita uma expressiva distância entre a democracia brasileira de hoje e a ideia de democracia constitucional proposta pelo constitucionalismo popular e o constitucionalismo latinoamericano.

Desse modo, será analisado o contexto no qual se delineou o constitucionalismo latino-americano, bem como a perspectiva apresentada pelo constitucionalismo popular, evidenciando a base comum que permite o diálogo entre essas duas teorias, utilizando como referência teórica principal o pensamento de Roberto Gargarella. A partir dessas teorias, será identificado o contexto democráticoconstitucional pós-88 no Brasil, demonstrando os limites institucionais evidenciados no contexto que resultou na queda do Decreto-Lei 8.243/2014, sem deixar de reconhecer, não obstante todos os recuos, que a Constituição de 1988 representa também uma forte tentativa e ao mesmo tempo, tímida e inicial expressão de um movimento histórico vigoroso de dar ao povo o papel fundacional que o constitucionalismo lhe conferiu.

O método de abordagem que será utilizado é o dedutivo, com método de procedimento monográfico e técnica de pesquisa bibliográfica.

\section{CONSTITUCIONALISMO POPULAR E CONSTITUCIONALISMO LATINO-AMERICANO: SOBERANIA POPULAR E NARRATIVAS CONSTITUCIONAIS EM DIÁLOGO}

O constitucionalismo popular propõe uma nova perspectiva para o debate que envolve a tensão entre constitucionalismo e democracia: avançar a reflexão para além do binômio judicial review versus parlamento, envolvendo os cidadãos no processo de construção de sentido da constituição.

O envolvimento popular na construção da interpretação constitucional proporciona a consolidação da ideia de que nas democracias não haveria uma palavra final e definitiva acerca do que é a constituição. As questões poderiam ser constantemente reavaliadas a luz de novas possibilidades e compreensões, forjadas no dialogo democrático. A democracia pressupõe disputa, conflito e reflexão crítica constante. $\mathrm{O}$ constitucionalismo busca estabelecer limites a essa disputa, e pode continuar a fazê-lo 
desde que possa ser reinterpretado constantemente via deliberação e dialogo, nas diversas esferas da vida.

Uma primeira questão a ser pensada são os desenhos institucionais. Para tornar uma proposta dessa envergadura experiência concreta, se fazem necessárias instituições que permitam realizar esse tipo de diálogo e debate. É necessário rever a estrutura que organiza o poder, a sala de maquinas ${ }^{3}$ da constituição.

Porém, uma pergunta ainda preliminar deve ser colocada: a participação popular na política se faz necessária para atender a qual finalidade? Porque é necessário recuperar a atuação da soberania popular para além dos momentos fundacionais ou extraordinários na América Latina - no Brasil, no caso deste trabalho - de modo especial? Uma possível resposta a essa questão está na pergunta colocada por Gargarella (2014, p. 347-348): qual o principal problema que o constitucionalismo se propõe a responder na América Latina?

A desigualdade. Se o constitucionalismo na América Latina se propõe a responder ao drama da desigualdade, é necessário pensar em como atuar na realização de uma igualdade real. Operou-se um descolamento entre direito e povo, uma profunda separação entre o direito e as comunidades nas quais ele se aplica. Este tipo de dissociação não só existe na América Latina, mas encontra aqui uma ressonância muito particular. A desigualdade presente nesta região tende a traduzir-se também em um direito desigual, concentrado nas mãos de poucas elites, normalmente pouco envolvidas com as necessidades da coletividade (GARGARELLA, 2013, prólogo).

As perspectivas comuns adotadas pelo constitucionalismo latino-americano e pelo constitucionalismo popular (e pelo constitucionalismo débil) propõem uma desconcentração do poder político, através de atribuição de mais poder à cidadania para deliberar e decidir sobre a política, o Estado, o social, sobre o direito e a constituição. A igualdade de acesso ao poder político poderá se traduzir em igualdade nos demais âmbitos. Veja-se que o lugar de origem das reflexões é distinto. O constitucionalismo popular foi pensado a partir do contexto norte-americano, porém não restam dúvidas da pertinência que essa proposta guarda com o contexto latino: recuperar o papel decisivo e potencializador da cidadania na criação e gestão do direito (GARGARELLA, 2013, prologo), repensando, criticamente, a inclinação existente a adotar alguns aspectos do constitucionalismo europeu do pós-guerra, especialmente, a supremacia judicial e o desdém pelos movimentos sociais como geradores de novos sentidos constitucionais (ORTEGA, 2013). 
Prelúdios de um constitucionalismo popular e latino-americano no Brasil? participação democrática pós-88 e queda do Decreto-lei 8.243/2014

É sabido que os textos constitucionais não contem chaves magicas de resolução de problemas, mas que trazem um leque de importantes possibilidades para a superação destas crises, através de transformações institucionais e culturais. A partir desta constatação, é necessário compreender a lógica das constituições, seus pressupostos básicos, normalmente associados com a filosofia publica dominante em determinado espaço-tempo. Tais pressupostos são de importância central pois são traduzidos na forma que se constituem as instituições (GARGARELLA, 2015, P. 347-350).

Para isso, é necessário compreender mais profundamente, em um primeiro

momento, o contexto que se delineou o constitucionalismo latino-americano. Em um segundo momento, será descrita a perspectiva apresentada pelo constitucionalismo popular. A ideia inicial, de que existe uma base comum que permite o diálogo entre essas duas teorias já está posta e poderá ser melhor verificada adiante. A partir dessas perspectivas teóricas, será analisado o contexto democrático-constitucional pós-88 no Brasil.

\subsection{O constitucionalismo latino-americano}

A América Latina é um exemplo claro e evidente das dimensões que a desigualdade pode atingir. A complexidade cultural e política dessa porção de mundo desafia o pensamento político-constitucional a pensar novas formas de compreender e interpretar sua história democrática, que possibilitem a existência de projetos concretos comprometidos com a igualdade, com a liberdade, com as virtudes republicanas.

Nesse sentido, Roberto Gargarella possui uma leitura importante do contexto latino, ao afirmar a existência de cosmovisões constitucionais muito distintas, que logicamente derivam modelos constitucionais muito distintos. Essa questão não impede a existência de uma filosofia igualitária que permeia seus contextos, proposta como base para se reorganizar as instituições, que se expressa em duas questões principais: por um lado, existe uma forte solicitação por um autogoverno coletivo, isto é, pelo igual direito de todos a decidir sobre os destinos da vida coletiva; por outro lado, existe um também uma demanda por formas diversas de exercício da autonomia individual, asfixiada pelo perfeccionismo moral que foi imposto pelo centro colonial, ainda naquele período (GARGARELLA, 2015, p. 349).

É possível perceber um modelo latino de constitucionalismo bastante peculiar, sintetizado na seguinte formula: liberdades políticas restringidas e liberdades civis e econômicas amplas. As instituições que derivam desse modelo asfixiam a 
complexidade e são pouco permeáveis a participação democrática. O resultado disso é um sistema institucional que favorece as desigualdades. Com a emergência da questão social, no início do século $\mathrm{XX}$, aconteceu uma primeira etapa do reformismo constitucional na América Latina, o qual incorporou nas constituições, instituições que traduziam de algum modo o projeto rousseuniano: direitos sociais, direitos dos trabalhadores, organizações sindicais, proteção às minorias desfavorecidas, etc. ${ }^{4}$. Contudo, a reforma foi parcial. A parte destinada a organização do poder permaneceu com um desenho liberal-conservador, resultando em um desenho institucional problemático: de um lado, amplo rol de direitos, que exigiriam instituições e práticas de participação política ativa da comunidade, majoritarismo político, em suma, o cultivo das virtudes republicanas. Do outro lado, uma sala de máquinas com características típicas do ideário liberal-conservador. A tensão interna se expressa na manutenção de uma estrutura de poder impermeável às crescentes demandas sociais provenientes da sociedade civil. (GARGARELLA, 2009, p. 18; GARGARELLA, 2015, p. 356).

A afirmação de um modelo constitucional dessa natureza enfraquece o constitucionalismo e a democracia, ao reduzir suas potencialidades e tensões a uma contradição impossível de ser enfrentada. Não há como realizar um projeto igualitário, de participação cidadã na construção do direito e da democracia a partir de instituições que mantem o poder de decisão concentrado em poucas mãos e institucionalmente salvo do jogo democrático.

Foi esse contexto que gerou a necessidade de se pensar um novo constitucionalismo latino-americano. Dalmau (2008, p. 01-03) afirma que a novidade do constitucionalismo latino-americano consiste na tentativa e na experiência concreta de se instaurarem assembleias constituintes efetivamente resultantes de movimentações cívicas, com propostas políticas alçadas em cenários de forte conflito político, econômico e social.

Operou-se um resgate da soberania popular, com a participação do poder constituinte diante da necessidade de uma nova transição política e jurídica, dando origem a uma nova rodada de constituições amplas e detalhadas, que expressam de forma vivaz as demandas cívicas mais complexas, próprias do contexto multicultural dessa região, marcado por profundas desigualdades e violações de direitos fundamentais (DALMAU, 2008, p. 02-04). Esse segundo movimento de independência na região ultrapassou as elites dos países e se deu a partir do povo. A identificação da escassa identidade existente nas democracias representativas entre representantes políticos e seus representados deu R. Fac. Dir. UFG, v. 41, n.2, p. 169-195, maio /ago. 2017 
Prelúdios de um constitucionalismo popular e latino-americano no Brasil? participação democrática pós-88 e queda do Decreto-lei 8.243/2014

origem a novos desenhos institucionais, que permitissem uma maior participação da cidadania na política (DALMAU, 2008, p. 04). Iniciou-se um processo de entrada na sala de maquinas das constituições latinas, com modificações sensíveis em seus mecanismos de funcionamentos.

É importante evidenciar que existem diferenças significativas entre as mudanças constitucionais operadas nos países latinos, pelos seus contextos culturais, políticos, sociais e econômicos distintos. UPRIMNY (2011, p. 108) entende que as mudanças constitucionais se distinguem por três razões: i) pela origem e natureza dos processos ( resultado de quedas ditaduras, reforma de regimes democráticos por falta de legitimidade, mudança no sistema de partidos), ii) por sua intensidade ( alguns países adotaram novas constituições, muito distintas das anteriores; outros mantiveram as existentes, realizando mudanças menos fortes), iii) por sua orientação (algumas são expressão de um constitucionalismo experimental e transformador, outras mantem orientações próprias de políticas neoliberais).

Não obstante essas importantes distinções, que resultam em tendências constitucionais bastante distintas, com potencialidades e orientações próprias, as razões comuns que perpassam esses contextos permitem posiciona-las no novo constitucionalismo latino-americano.

Tanto Dalmau (2008, p. 07-11), quanto Uprimny (2013, p. 109-112) compreendem que esses traços comuns são característicos de assembleias constituintes que gozaram de participação popular e social, resultando em textos que incorporaram amplos mecanismos de democracia direta, mesclados com a os clássicos mecanismos próprios democracia representativa. Consultas populares, referendos, criação de conselhos de controle e gestão pública, fóruns de deliberação e decisão, maior descentralização no exercício do poder político, acesso direto dos cidadãos ao poder judicial (sem necessidade de advogados, elementos técnicos e outra exigências formais) resultaram em uma sala de maquinas com modificações importantes, mais aptas a promover um real envolvimento da cidadania com a política e a constituição. Percebe-se a adoção de uma estratégia global de maior equilíbrio entre os poderes, com vistas a superar o excesso de poder presidencial, tão característico na América Latina ${ }^{5}$.

Políticas de igualdade foram estabelecidas, ao lado de um direito de propriedade matizado pela admissibilidade de regimes de propriedades coletivas ou compartilhadas. Os desenhos institucionais ganharam contornos permeáveis à participação cidadã. Os direitos coletivos dos povos indígenas foram fortemente 
reconhecidos, no marco da modificação de um entendimento de estado como unidade nacional, resultante da homogeneização de diferenças, rumo a uma compreensão de estado permeado pelo pluralismo, como nações pluriétnicas e pluriculturais, que estabelecem como princípio constitucional a promoção da diversidade (UPRIMNY, 2013, p. 110-124; DALMAU, 2008, p. 05-11).

Uprimny (2013, p. 111) chega a afirmar um constitucionalismo da diversidade. O reconhecimento da diversidade étnica e cultural vem acompanhado do reconhecimento da diversidade e igualdade religiosa. Grupos tradicionalmente discriminados (comunidades indígenas e negras) passam a ter direitos especiais de representação política em suas comunidades, que incorporaram suas línguas como língua oficial e reconhecem um poder judicial próprio, com autonomia a determinados territórios para solucionar seus conflitos de acordo com suas cosmovisões culturais. Direitos sociais, econômicos e culturais, como educação, saúde, vivencia, foram reconhecidos de forma avançada ao lado de direitos coletivos, como direito ao meio ambiente, a agua, a natureza ("Pachamama”), ao "bem viver". Questões de gênero e raça permearam definições de políticas de igualdade. A questão da função econômica do Estado recebeu tratamento bastante distinto nas cartas constitucionais, face a dificuldade de encontrar uma tendência econômica comum a todos os países.

Ainda, é necessário chamar a atenção para um elemento importante: a experiência constitucional latina forjada no interior do constitucionalismo latinoamericano permitiu uma maior estabilidade dos governos civis na região. Quedas presidenciais ocorreram sem intervenção militar. Tendo em vista a realidade histórica e política latino-americano, trata-se de uma mudança profunda nestes regimes democráticos, considerando a frequência das ditaduras militares que ocorreram na região durante os séculos XIX e XX (UPRIMNY, 2013, p. 121).

A proposta normativa do constitucionalismo latino americano não está esgotada nas experiências constitucionais da região. Ainda há um longo caminho a ser percorrido. Afinal, a entrada na sala de maquinas foi sutil, diante da solidez que esses sistemas de poder adquiriram no tempo e da credibilidade que ainda possuem. O medo do popular, a falsa ideia de participação aliada a massas desorganizadas típicas de um regime totalitário ainda confundem e impedem uma compreensão adequada do que seria um regime autenticamente democrático e dialógico.

Nesse sentido, é bastante pertinente pensar a partir da crítica que Gargarella (2013, p. 10-13) tece ao próprio sistema de freios e contrapesos, construído para enfrentar R. Fac. Dir. UFG, v. 41, n.2, p. 169-195, maio / ago. 2017 
Prelúdios de um constitucionalismo popular e latino-americano no Brasil? participação democrática pós-88 e queda do Decreto-lei 8.243/2014

uma lógica de guerra, resistente ao desenvolvimento de diálogos institucionais e diálogos com a cidadania. Ou seja: há muito que refletir e experimentar. Porém, os caminhos existem. O constitucionalismo popular se coloca como um deles.

\subsection{O constitucionalismo popular}

O constitucionalismo popular permite repensar a relação entre constituição e povo, política e direito, a partir de uma nova leitura: propõe um debate acerca do papel que o povo deve ocupar nas decisões e discussões dos temas públicos relacionados a organização da vida em comunidade e dos sentidos da constituição.

Sua proposta consiste em considerar que o povo deve recuperar o lugar central da vida constitucional de suas comunidades. Trata-se de uma pretensão que busca colocar em questão muitos dos princípios tradicionais mais consolidados no constitucionalismo: o constitucionalismo popular nos convida a pensar novamente sobre o papel da cidadania na história constitucional (GARGARELLA, 2013).

Joel Colón Rios (2013, p. 02 e ss.) faz o mesmo convite, porém o nomina de constitucionalismo débil. Propõe pensar a relação entre constitucionalismo e democracia para além do debate judicial review versus parlamento e maiorias, propondo pensar o demos como cidadania que ultrapassa a esfera do Estado e atua na construção da constituição. Recomenda mudanças institucionais que permitam um experimentalismo democrático ${ }^{6}$ autêntico.

Ambas as perspectivas colocam a relação entre direito e política a nu, tornando clara a ausência de limites claros entre direito constitucional e política ${ }^{7}$, necessárias para pensar democracias constitucionais comprometidas com a soberania popular.

Ortega (2013) define muito bem as ideias que compõem o constitucionalismo popular: i) todos devem participar da configuração do direito constitucional através de suas ações políticas; ii) papel central ao exercício da cidadania na interpretação constitucional, desmistificando visões sobre a decisões dos tribunais; iii) impulso maior à participação popular nas estruturas políticas e econômicas; iv) mudança no sistema de controle de constitucionalidade, de modo que nenhum dos poderes políticos constituídos detenha a supremacia da interpretação constitucional em relação aos demais e ao povo.

Há um resgate da relação entre direito e política, compreendida de forma de forma mais abrangente, trata-se de duas fases distintas de um processo social complexo. 
A política deve ser apreendida como algo mais complexo que a mera vontade e decisão e o direito não é somente pura racionalidade. Ambos se imbricam reciprocamente e se interpenetram. A constituição é o ponto de confluência destas realidades, um nomos jurídico-político e não só jurídico (ORTEGA, 2013).

É necessário rever a compreensão elitista de que os poderes públicos são os melhores interpretes da constituição. Não somente: é preciso rever a compreensão equivocada de que o povo é necessariamente contrário a todos os entendimentos expressos pelos poderes constituídos. As questões não são matemáticas. O ponto central é elaborar uma doutrina constitucional como uma agencia coletiva, na qual o protagonista é o povo. É popular porque distribui amplamente a responsabilidade sobre a constituição e reforça o papel das pessoas pela sua interpretação (ORTEGA, 2013).

O poder judiciário, nesse sentido, é um agente cuja tarefa é ser um líder de opinião, sem impor-se como única e possível visão. Tanto o povo quanto os juízes podem se equivocar, por isso a necessidade de debate e diálogo entre povo e instituições. É importante desconstruir a ideia de que o direito constitucional é uma tarefa difícil para os cidadãos comuns e ainda insistir que os juízes estão necessariamente a serviço da sociedade (ALTERIO, 2013). As Cortes Constitucionais fazem parte da política e logicamente que suas interpretações da Constituição serão influenciadas por esse contexto. Daí a necessidade que a constituição tenha um significado para o povo, politicamente ativo e atuante na construção do espaço político, afinal, dessa forma, também produz os conteúdos que influenciarão na construção das decisões dos Tribunais acerca da interpretação constitucional. A constituição continua sendo vinculante, impondo os limites próprios que o constitucionalismo propõe. O que seria inovador é que os poderes políticos realizam sua interpretação em pé de igualdade com a comunidade. Ou seja: a construção político-popular da interpretação constitucional se dá na política e esta se faz presente nos Tribunais (ORTEGA, 2013).

Nesse mesmo sentido, Colón Rios (2013) propõe uma concepção de constitucionalismo de acordo com o qual a constituição deve permanecer permanentemente aberta para importantes transformações. Sob esse constitucionalismo "fraco" não existe uma constituição acabada. Trata-se de uma concepção consistente com um compromisso sério com a democracia. Isso supõe que a democracia não é exaurida na legislatura e governança diária, mas se estende a deliberar e decidir sobre o próprio conteúdo da constituição. 
Prelúdios de um constitucionalismo popular e latino-americano no Brasil? participação democrática pós-88 e queda do Decreto-lei 8.243/2014

A distinção operada por Colón Rios (2013, capítulo 2) entre democracia de governança diária (decisões ordinárias) e democracia de leis fundamentais (decisões essenciais) deixa claro que cada uma dessas dimensões exige diferentes níveis de engajamento popular. Entende que a participação cidadã se opera nas decisões essenciais, mais do que nas ordinárias, que seriam deixadas por conta da legislatura. A dimensão das decisões essenciais contempla a relação do povo com sua constituição. Não se concentra na adoção ou conteúdo das leis ordinárias ou no debate de quem teria a palavra final para interpretar a constituição, mas em como o regime constitucional foi instituído e como a constituição pode ser alterada. Concentra-se sobre o modo pelo qual cidadãos podem participar no processo de construção da constituição e na reforma constitucional.

Os constitucionalistas populares, no mesmo sentido, evidenciam que há valores mais importantes que a clareza e a certeza que um direito interpretado pelos tribunais e constituído apenas nas salas legislativas supostamente produz (ALTERIO, 2013). Os princípios constitucionais e as ideias que nascem fora dos tribunais são cruciais para expandir as possibilidades de desenvolvimento constitucional e aliviar as tensões entre o direito constitucional e a cultura em que este opera. Desse modo, o que está no centro do argumento constitucional é a controvérsia política acerca da democracia (ALVAREZ, 2013).

A abertura democrática e a participação popular são dois componentes essenciais da democracia. Muito mais do que a tomada de decisão majoritária dentro das legislaturas: democracia tem uma segunda dimensão que requer olhar para a forma como os cidadãos comuns podem mudar as leis fundamentais. A genuína constituição democrática permite a participação dos cidadãos nas políticas constitucionais, a qual é bem diferente de obter o apoio do povo para uma decisão ou possuir a competência de falar em seu nome (COLÓN RIOS, 2013, capítulo 2).

O conteúdo constitucional é colocado sob a alçada da cidadania, permitindo que a concepção de justiça seja constantemente atualizada, revisitada e submetida a análise crítica por parte da cidadania. A ideia de princípios abstratos intocáveis, no topo do constitucionalismo, é incoerente com a ideia de democracia constitucional, que pressupõe uma comunidade de pessoas capazes de se autogovernar, definindo o conteúdo de suas normas com igualdade de condições nesse debate. Não faz sentido que o conteúdo constitucional fique sob a alçada de filósofos políticos ou gerações passadas, é necessário que a concepção de justiça esteja sempre aberta. Nessa perspectiva, é possível 
desenvolver uma concepção de constitucionalismo mais sensível aos ideais de participação popular na abertura democrática (COLÓN RIOS, 2013, capitulo 2).

Uma das questões que chama atenção no pensamento de Joel Colón Rios é a resposta que encontra para o medo histórico das maiorias realizando rupturas institucionais, como uma forma de justificar a resistência à participação popular na definição da política e da constituição: entende que justamente a abertura democrática constante para a definição do que é a constituição enfraquece a necessidade de instauração de episódios de ruptura institucional, uma vez que a atualização constante da ordem instituída via debate democrático tornaria quase que desnecessárias mudanças institucionais abruptas e tão profundas de uma única vez (COLÓN RIOS, 2013, capitulo 2).

O exercício da deliberação, do diálogo e do debate fortalece a cultura democrática e permite que a formação de maiorias se constitua a partir da ampla participação cidadã, na qual várias vozes se fazem presentes e qualificam a discussão com a diversidade de compreensões, possibilidades e sentidos. A resposta democrática e constitucional ao drama da desigualdade passa pela via da igualdade de participação na política.

O desenvolvimento e fortalecimento de uma cultura democrática, gera condições materiais favoráveis ao fomento e sustento de reformas constitucionais que permitam cada vez mais a abertura da sala de maquinas da constituição. Um movimento favorece e propicia condições ao outro. Até porque a resistência a alterações na organização do poder político é comprovada. É necessário que a cidadania promova formas de pressão, que impulsionem novos desenhos institucionais favoráveis ao experimentalismo democrático. O constitucionalismo latino-americano demonstra isso. É necessário começar a experimentar a expansão das formas de participação cidadã a partir dos instrumentos disponíveis, tendo em vista a realização de reformas mais profundas e integrantes de um projeto constitucional e democrático igualitário.

\section{PARTICIPAÇÃO POPULAR PÓS-88 E O DECRETO-LEI 8.243-2014}

A participação popular está presente na Constituição Federal de 1988 em variadas perspectivas e matizes. Uprimny (2011, p. 108 e ss) afirma que a Constituição brasileira demarcou o início de um processo de democratização que começou a delinear o que se chamou mais tarde de constitucionalismo latino americano. 
Prelúdios de um constitucionalismo popular e latino-americano no Brasil? participação democrática pós-88 e queda do Decreto-lei 8.243/2014

Esta Constituição configurou o marco de um novo momento histórico, político e institucional marcado por outro modelo de relacionamento entre o estado e a sociedade civil, especialmente no que se refere à construção e operacionalização de políticas públicas. Removeu o "entulho autoritário”, criando um arcabouço institucional voltado para a garantia dos direitos políticos, civis e sociais dos cidadãos (BARROS, RIBEIRO, 2005, p. 01).

Não obstante, é muito claro que a Constituição Federal de 1988 não pode ser colocada no marco de um constitucionalismo popular e débil. A rigor, até mesmo é questionável posiciona-la no contexto do novo constitucionalismo latino americano. Sua sala de máquinas permanece caracterizada por todos os elementos levantados na crítica de Roberto Gargarella e não é possível perceber a participação cidadã profunda e ampla como propõem as teorias visitadas anteriormente.

Não obstante essas fragilidades, é possível identificar significativas inovações nas várias formas de participação popular previstas no texto de 1988, as quais produziram resultados positivos na construção da democracia. Percebe-se que tanto os mecanismos de participação, como seus resultados, são propositalmente pouco divulgados. Estes são alguns dos limites que se colocam ao desenvolvimento do potencial democrático no Brasil.

A grande mídia realmente não demonstra interesse em potencializar essa dinâmica democrática fundamental. Porém, ela existe e é fundamental para que a relação entre os direitos políticos e os direitos civis possam ser equalizados, fazendo com que a participação política seja acompanhada pela ampliação dos direitos civis e o enfrentamento das desigualdades sociais (BARROS, RIBEIRO, 2005, p. 01).

Além dos mecanismos clássicos previstos no artigo 14 da Constituição Federal - referendo, plebiscito e iniciativa popular - a institucionalização da participação social se deu através dos conselhos ${ }^{8}$, a serem compostos por representantes de diferentes setores da sociedade, do Estado e, em alguns casos, dos trabalhadores. A partir dos anos 2000, a realização de conferências passou a ser disseminada como mais uma forma de participação, que auxilia no mapeamento das demandas e na construção de consensos entre os movimentos sociais nos momentos que antecedem a formulação de políticas pelo poder executivo (FERRAREZI, OLIVEIRA, 2012, p. 05).

Várias pesquisas apontam para a efetividade destes instrumentos de participação popular. Segundo Pogrebinschi (2013, p. 275), é possível perceber a efetividade dos resultados das conferencias, bem como sua ocorrência repetida, que 
denotam seu processo de institucionalização de modo claro. As conferências de políticas para as mulheres realizaram, em sua terceira edição (2011), realizar a "avaliação e aprimoramento das ações e políticas que integram o II Plano Nacional de Políticas para Mulheres e definição de prioridades' (Decreto de Convocação da II CNPM, de 15/3/2011), deixando evidente que o ciclo de políticas públicas no Brasil vem sendo alterado por este experimento participativo.

As conferências nacionais têm influência na definição da agenda política, ao incluírem novas áreas de atuação - como é o caso das políticas para minorias, antes desprovidas de planos nacionais e políticas específicas, bem como impactam na formulação das políticas, ao proverem diretrizes passíveis de orientar o governo na elaboração de normas e planos nacionais, além de programas e ações mais pontuais dos diversos ministérios, secretarias e conselhos. Ainda, facultam o monitoramento das políticas existentes, inclusive daquelas elaboradas supostamente com respaldo do próprio mecanismo conferencial. Propiciam o redesenho do processo político-decisório no Brasil, de modo a tornar a participação social e a deliberação conjunta entre governo e sociedade civil uma de suas etapas constitutivas. Pode-se afirmar que as conferências nacionais consistem em robusto exemplo do experimentalismo democrático brasileiro (POGREBINSCHI, 2013, p. 275 e ss.). Na esfera federal é possível identificar a existência de 40 (quarenta) conselhos que atuam na esfera federal, sem contar os conselhos estaduais e municipais ${ }^{9}$.

Considerando estes dados e elementos teóricos, é possível afirmar que a participação popular é um fenômeno institucionalizado no Brasil, em caminho de expansão e consolidação. Pesquisas comprovam esse fenômeno. Segundo Rocha (2009), a expansão de instituições participativas no Brasil constitui um movimento auspicioso de pluralização dos espaços de poder e da capacidade de interferência de grupos sociais que sem estas instituições, estariam excluídos da capacidade de influir nas decisões públicas.

Verifica-se que estes experimentos de participação cidadã se aproximam em alguma medida daquilo que propõe o constitucionalismo popular, no que diz respeito a participação do povo na construção da decisão política. Porém, o desenho institucional assumido pela Constituição Federal de 1988 ainda oferece obstáculos fortes a perspectiva proposta pelo constitucionalismo latino-americano e também do constitucionalismo popular: a participação popular existe, repercute na definição da política, porém ainda permanece restrita a estes espaços delimitados de exercício do poder popular. A decisão final, por sua vez, ainda permanece "salva" do jogo democrático. 
Prelúdios de um constitucionalismo popular e latino-americano no Brasil? participação democrática pós-88 e queda do Decreto-lei 8.243/2014

Um exemplo claro disso se verifica na repercussão causada pela publicação do Decreto-Lei 8.243-2014, chamado pela grande mídia de decreto bolivariano, bolchevique, e outros atributos correlatos. Houve uma intenção clara de qualificar este ato político e legislativo como uma tentativa de instaurar categorias socialistas no Brasil. Houve quem disse ser uma "mudança de regime por decreto".

O Decreto-Lei 8.243/2014, originado do Poder Executivo, tinha como objetivo geral instituir a Política Nacional de Participação Social - PNPS e o Sistema Nacional de Participação Social - SNPS. Seu texto não expressa nada de extraordinário para um regime democrático. Objetiva, segundo seus próprios termos, institucionalizar a participação social como método de governo ${ }^{10}$. Organizado em 18 artigos, o Decreto apresenta também uma espécie de glossário de seus termos e instrumentos mais importantes, que reconhecem estruturas já existentes, inaugura novos e surpreende com uma definição de sociedade civil bastante ampliada (BARROS, RIBEIRO, 2005, p. 05), ultrapassando uma dimensão meramente institucional ao reconhecer essa condição ao cidadão, aos coletivos, aos movimentos sociais institucionalizados ou não institucionalizados, suas redes e suas organizações. Reforça a legitimidade dos conselhos de políticas públicas, das comissões de políticas públicas, das conferências nacionais, da ouvidoria pública federal, das mesas de diálogo, dos fóruns Inter-conselhos, das audiências públicas, das consultas públicas e dos ambientes virtuais de participação social $^{11}$.

A ampliação do significado atribuído a sociedade civil foi uma das fortes inovações do decreto, além da regulamentação a nível federal dos fóruns inter-conselhos, o reconhecimento das mesas de diálogo e dos ambientes virtuais específicos como instrumentos de participação social. Ainda, institucionalizou-se o reconhecimento de mecanismos que possibilitam a participação referente aos programas e políticas públicas, como conselhos, conferências, ouvidorias, mesas de diálogo, consultas públicas, audiências públicas e ambientes virtuais de participação social e a possibilidade aberta de inclusão de outros mecanismos que surgirem (BARROS, RIBEIRO, 2005, p. 10-11).

Após essa análise parece claro que o decreto não traz nenhuma inovação tão substancial e estranha a um regime democrático e constitucional que mereça a resistência social ocorrida. Reconheceu instrumentos existentes, reforçando sua eficácia e operacionalização, introduziu novos mecanismos no mesmo sentido dos já existentes e parece constituir uma tentativa de se estabelecer um marco regulatório forte para a participação popular. 
Os argumentos favoráveis ao decreto endossam seu espirito republicano ao institucionalizar e reforçar os instrumentos de participação democrática direta previstos na Constituição Federal. O governo federal e setores alinhados com suas políticas, se manifestaram alegando que o decreto tão somente fortalece mecanismos já existentes, estabelecendo um marco regulatório especifico, resultante da aceleração da pauta das reformas políticas produzidas pelas manifestações e movimentos sociais ocorridos no país em junho de 2013. Os contrários ao Decreto, partidos de oposição e grande mídia nacional, repudiam rotulando-o como expressão da "ditadura petista" ou como busca por uma "hegemonia socialista". Para estes, o decreto teria características totalitárias na medida em que estaria corroendo a democracia representativa, enfraquecendo o Congresso Nacional, na medida em que foi feito sem a participação do legislativo (BARROS, RIBEIRO, 2005, p.17-18).

A compreensão das razões que alimentam o decidido combate dos grandes jornais brasileiros, requer um enquadramento mais amplo. Por um lado, essa atitude expressa a maneira como, historicamente, e em nome da liberdade de expressão, setores mais conservadores da imprensa do país vêm se colocando frente às proposições de democratização dos meios de comunicação social. Tal questão foi aventada em vários artigos publicados sobre esse assunto e realmente demonstra total procedência.

O contexto criado com a publicação do decreto traz a nu os entraves institucionais (e culturais) à consolidação de uma pratica político-constitucional nos moldes propostos pelo constitucionalismo popular e pelo constitucionalismo latinoamericano. Primeiramente porque deixa claro a forte resistência a qualquer possibilidade de institucionalização mais profunda da participação popular na política no Brasil. Delata um ambiente institucional hostil a igualdade, que torna evidente a afirmação feita pelos adeptos do constitucionalismo latino-americano: nosso desenho institucional favorece a desigualdade.

Desqualificar uma proposta política, reduzindo-a a um argumento políticopartidário tem sido uma pratica constante e potente de enfraquecimento das tentativas de construção de espaços participativos, populares, dialógicos. Um dos fortes argumentos contrários ao decreto consiste na afirmação de que consiste em uma tentativa de enfraquecimento da democracia representativa e do Poder Legislativo. Isso porque o governo a época da publicação do decreto era petista. Logo, o esforço era disseminar a convicção de que todos esses experimentos de consolidação democrática eram indícios da instauração de um regime totalitário e socialista. 
Prelúdios de um constitucionalismo popular e latino-americano no Brasil? participação democrática pós-88 e queda do Decreto-lei 8.243/2014

Thamy Pogrebinschi (2016) desfaz esse equívoco ao afirmar que os dados revelam que representação e participação não competem entre si, porém reforçam-se mutuamente. Segundo ela, o Congresso Nacional está mais em sintonia com os mecanismos participativos do que parecem supor os próprios parlamentares que sustaram a aplicação do Decreto Presidencial 8243/14. A pesquisadora enumera uma serie de conclusões extraídas de sua pesquisa, as quais valem ser destacadas pela clareza que possuem ao deixar as questões ideológicas desnudadas.

A primeira delas informa que as conferencias nacionais existem desde 1941, e deste ano até o ano de 2002, antes do Partido dos Trabalhadores assumir o Poder Executivo, foram realizadas 42 (quarenta e duas) conferencias nacionais. Desse modo, a metade delas ocorreu durante o governo do PSDB, partido que se opôs ao decreto. O Plano Nacional de Direitos Humanos, que é relembrado e associado ao decreto 8243/14, foi produto da $11^{\mathrm{a}}$ edição de uma conferência nacional que o PSDB - e não o PT - criou e institucionalizou. Cruzando-se todos os atos legislativos do Congresso Nacional com as deliberações finais das conferências nacionais no período entre 2003 e 2010, verifica-se que as mesmas impactam positivamente na agenda do Legislativo: 1477 projetos de lei, 125 leis ordinárias e complementares e 6 emendas constitucionais aprovadas no período são inteiramente convergentes com as demandas finais das conferências nacionais (POGREBINSCHI, 2013).

Partindo da análise de Pogrebinschi (2013), é possível concluir que mecanismos nacionais de participação não são aproveitados unicamente pelo PT. Os partidos de oposição propuseram $31 \%$ dos atos legislativos tramitados no Congresso que são convergentes com as deliberações das conferências nacionais realizadas no período. O PSDB e o DEM/PFL foram juntos autores de 23,8\% das respostas legislativas convergentes com os resultados das conferências nacionais. Isso equivale a praticamente o mesmo volume de atos legislativos propostos pelo PT, 25,8\% - o que desmente a acusação de que o governo usa os mecanismos participativos para impor suas políticas. $\mathrm{O}$ argumento de que estes mecanismos de participação fortalecem o Executivo em detrimento do Legislativo, não tem qualquer fundamento. Veja-se que $56 \%$ da legislação aprovada no Congresso convergente com as recomendações das conferências nacionais têm iniciativa no próprio Poder Legislativo - ou seja, mais que $15 \%$ das iniciativas que lhe cabem no volume total da legislação promulgada desde 1988. Na medida em que a agenda do Legislativo converge com a agenda da sociedade civil, o Congresso tem bem mais chances de ver aprovados os seus projetos de lei. A última acusação mais 
contundente feita ao decreto, consistia na afirmação de que existia uma tentativa de criar um novo sistema político por via inconstitucional, o que não tem procedência, vez que instrumentos de participação social ampliam a democracia representativa. Os dados denotam que as políticas novas criadas no âmbito dos direitos das minorias foram, em sua maior parte, conquistas decorrentes dos mecanismos institucionais de participação social, que reforçaram a agenda do Legislativo amplamente. (POGREBINSCHI, 2016).

Vale lembrar que a minuta do Decreto foi objeto de consulta popular no portal Participa.br do Governo federal, obtendo, durante os 30 dias em que esteve no ar entre julho e agosto de 2013, 700 contribuições e cerca de 200 visitas, conforme informação da própria plataforma, gerenciada pela Secretaria Geral da Presidência da República, em $12 / 7 / 2014^{12}$.

A questão que se fez fortemente presente neste debate e que acabou por motivar a "derrubada" do decreto expressa possuir uma origem profundamente ideológica. Não só, envolve também uma disputa de poder da mídia e outros setores sociais a ela diretamente ligados. Não foram encontrados elementos de discussão teórica ou técnica que demonstrassem alguma consistência maior. Somente ataques que remetiam a chavões e lugares-comuns. A questão em jogo é a resistência manifesta à participação da cidadania na política. A intenção de quem opera a sala de maquinas é manter sua porta fechada.

Aqui se colocam os limites institucionais a uma maior potencialização da participação popular. A democracia brasileira perdeu significativamente uma possibilidade de robustecer seus fundamentos com a queda do Decreto-Lei 8243/2014. A vigência de um decreto deste porte traria ganhos significativos para a construção de um constitucionalismo popular (ou débil, democrático), e daria início a um processo de preparação do contexto cultural e institucional mais apto a uma reforma na sala de maquinas da Constituição. A ampliação dos espaços de participação cidadã proposta pelo decreto e a institucionalização mais clara dos mecanismos já existentes reforçariam a capacidade democrática de confrontar os poderes constituídos, potencializando a desestabilização de estados de coisas destinados a preservar a concentração do poder político.

O texto constitucional brasileiro contém elementos importantes trazidos pelo constitucionalismo latino-americano (função social da propriedade e da empresa, republicanismo, pluralismo político, liberdade de expressão, liberdade religiosa, direitos 
Prelúdios de um constitucionalismo popular e latino-americano no Brasil? participação democrática pós-88 e queda do Decreto-lei 8.243/2014

indígenas, direitos de minorias, direitos sociais), porém ainda é carente de envergadura institucional que sustente a concretização destes direitos.

Por outro lado, dados e pesquisas trazem conclusões interessantes acerca do amplo alcance dos mecanismos de participação popular na definição da política e dos direitos. Ou seja: é possível um constitucionalismo popular e latino-americano no Brasil e existe potencialidade democrática para tanto. Porém, o caminho é longo e extremamente trabalhoso. A questão central é concentrar esforços na reflexão teórica e na construção de uma práxis comprometida com a consolidação e ampliação desses mecanismos, plantando condições materiais para uma futura mudança institucional mais solida.

\section{CONSIDERAÇÕES FINAIS}

Após analisar o contexto que desencadeou a queda do Decreto-Lei 8243\2014 tornam-se muito claros os limites institucionais existentes a consolidação de um regime efetivamente democrático e constitucional, nos moldes colocados pelas perspectivas teóricas do constitucionalismo popular (ou débil) e pelo constitucionalismo latino americano.

No Brasil, a exemplo de muitos outros países, a soberania popular encontrase confinada a representação parlamentar e em algumas possibilidades de participação popular. O poder concentrado nas mãos dos governantes enxerga no poder popular uma ameaça. Não surpreende reconhecer que em toda América, ao longo de toda sua história, a resposta por parte do poder foi sempre a mesma: a intenção clara de disciplinar os grupos dissidentes, através do dinheiro e da coerção. Não basta traduzir a questão social em uma linguagem de direitos. A justiça que aqui se propõem requer um processo aberto e persistente de dialogo coletivo (GARGARELLA, 2015, p. 365). O problema da desigualdade seguira se reproduzindo se a atuação política ficar concentrada unicamente no desenvolvimento das políticas de transferência de renda, sem ocorrer uma maior distribuição do poder político. Sem igualdade no poder de decisão sobre a política, não se constrói igualdade em outros âmbitos.

As experiências possíveis da democracia brasileira demonstram o potencial latente que a participação popular carrega em si de influenciar nos rumos da política e da construção dos direitos constitucionais. São ainda tímidas, mas demonstram sua força nos poucos dados disponíveis (até a escassez de dados e de publicidade destes dados denotam o desinteresse dos poderes instituídos por tornar visível a potencialidade da cidadania). 
Se mecanismos de participação popular se institucionalizam e se tornam um componente regular da prática constitucional do estado moderno, "as constituições deixarão de serem olhadas com a reverência hipócrita do século 18 ” para se tornarem instrumentos de correção das injustiças existentes, a partir de sujeitos constitucionais comprometidos com a construção de seu significado democrático. Com isso, a legitimação democrática aumenta e a identificação da cidadania com sua Constituição gera combustível e cultura democrática apta a suportar e levar adiante as necessárias mudanças institucionais esperadas durante séculos pelo constitucionalismo (COLÓN RIOS, 2013, capitulo 2).

Não faz sentido continuar a proteger a rigidez de um modelo de constitucionalismo que alça sua justificativa na proteção de direitos fundamentais e de uma democracia, sacrificando-os dos mais variados modos. O medo do povo, da participação popular, é um mito teórico e político construído que merece ser desconstituído. Logicamente que os regimes autoritários deixaram suas marcas, que se expressam no temor das maiorias e na rigidez constitucional ao querer manter inegociável certos conteúdos constitucionais. A questão que se coloca é que, no mundo da vida, isso é negociado. Tornar isso desnudado contribui para atacar a raiz dos nossos maiores problemas políticos e constitucionais. Colocar a constituição nas mãos do povo significaria, de fato, retirar-lhe o substrato democrático de proteção dos direitos fundamentais? As elites políticas e os poderes constituídos não tem demonstrado grande interesse em salvaguardar esse substrato e a democracia segue perdendo, permanecendo um belo regime de fachada, que permanece encarcerada nas mãos de poucos.

Aumentar as possibilidades de vozes, de manifestações, de diálogos, de possibilidades de encontro real com o outro, demonstra-se mais em consonância com uma verdadeira teoria e pratica democrática e constitucional, do que aquilo que se enxerga nos dias de hoje.

Percebeu-se de toda reflexão que é necessário ir além da discussão que demarca certo maniqueísmo na discussão democrática: maiorias (legislativo) versus minorias (Judiciário). Primeiramente: a democracia ativa, concebida a partir de uma participação popular intensa, é algo muito distinto de mera agregação de preferencias, de maiorias decidindo questões ou aclamando situações. Basta pensar na situação política do Brasil nos últimos meses: o desfecho da situação política de fato refletiu o que a maioria dos cidadãos entendia como adequado, ou o debate ficou circunscrito a uma elite intelectual e política, concentrada no Legislativo, que se fez presente em passeatas 
Prelúdios de um constitucionalismo popular e latino-americano no Brasil? participação democrática pós-88 e queda do Decreto-lei 8.243/2014

pontuais? Pela extensão e complexidade de um país como o Brasil, isso é bastante visível e torna toda essa discussão bastante questionável. Ou seja: que tipo de legitimidade democrática existe hoje na ação do Legislativo, se essa participação permanece adstrita a um público fatiado, determinado, com acesso a alguma informação, justamente pelos desenhos institucionais pouco permeáveis e facilitadores de mobilização política e popular mais densa, ativa, ampla? Se existem canais permanentes de mobilização, de dialogo, de reinvindicação, grandes mobilizações desordenadas se tornam eventos muito ocasionais e raros, uma vez que a cidadania tem espaço permanente e concreto na definição dos rumos da política, da Constituição, da organização social. Em segundo lugar: o Judiciário não é o único guardião existente de minorias e sua ação pode tornarse bastante desconectada do que é possível chamar de compromisso com direitos fundamentais e com a democracia. No Brasil isso pode ser verificado de vários modos, inclusive através de pesquisas empíricas.

Concluindo e repetindo: o constitucionalismo popular que aqui se discute não requer a abolição do judicial review, mas apenas questiona a corte como instituição que dá a última palavra (ou a única, em muitos casos) sobre o que é a constituição. O debate deve permanecer aberto, mesmo com a corte desempenhando seu papel. O paradoxo é incontestável: é possível que constituições, constituídas para resolver um drama desigualdade - existam para aprofundar a desigualdade. Nesse sentido, a proposta do constitucionalismo débil, democrático, popular, de colocar os conteúdos constitucionais sob disputa política, permitindo que a participação popular ganhe força institucional, construindo condições materiais para novas configurações na sala de maquinas, apresenta-se como uma solida possibilidade de inverter esse jogo.

\section{REFERÊNCIAS}

ALTERIO, Ana Micaela. Neoconstitucionalismo y constitucionalismo popular frente a frente. In: ALTERIO, Ana Micaela; ORTEGA, Roberto Niembro. (Orgs.)

Constitucionalismo popular em Latinoamerica. Spanish Edition. México: Biblioteca Jurídica Porrúa, Escuela Libre del Derecho, 2013, Kindle Edition, Primeira Parte.

ALVAREZ, Luciana. Constribuciones al constitucionalismo popular desde la teoria crítica y la filosofia latinoamericana. In: ALTERIO, Ana Micaela; ORTEGA, Roberto Niembro. (Orgs.) Constitucionalismo popular em Latinoamerica. Spanish Edition. México: Biblioteca Jurídica Porrúa, Escuela Libre del Derecho, 2013, Kindle Edition, Primeira Parte. 
BARROS, José Marcio; RIBEIRO, Núbia Braga. O decreto da polêmica: disputas midiáticas em torno da participação social no Brasil. Revista Eletrônica do Programa de Pós-Graduação em Mídia e Cotidiano. Artigos Dossiê Comunicação e Cidadania, Número 5, dezembro 2014, p. 01. Disponível em:

<http://www.ppgmidiaecotidiano.uff.br/ojs/index.php/Midecot>. Acessado em 07 de agosto de 2016.

COLÓN-RIOS, Joel L. La constituición de la democracia. Trad. Graciela Riveira Munoz. Bogotá: Universidad Externado de Colombia, 2103. Kindle Edition.

DALMAU, Rubén Martinez. Asembleas constituyentes e nuevo constitucionalismo en América Latina. Tempo Exterior, n.17, jullo-decembro, 2008.

BRASIL, Decreto-Lei 8243/2014. Disponível em: <http://www.planalto.gov.br/ccivil_03/_Ato2011-2014/2014/Decreto/D8243.htm>. Acessado em 07 de agosto de 2016.

DWORKIN, Ronald. A virtude soberana: a teoria e prática da igualdade. Trad. Jussara Simões. 2 ed. São Paulo: WMF Martins Fontes, 2011.

FERRAREZI, Elisabete; OLIVEIRA, Clarice G. Reflexões sobre a emergência da participação social na agenda das políticas públicas: desafios à forma de organização burocrática do Estado. Anais do V Congresso de Gestão Pública, CONSAD. Escola de Administração Pública: Brasília, junho de 2012. Disponível em:

<http://www.segplan.go.gov.br/post/ver/167051>. Acessado em 07 de agosto de 2016.

GARGARELLA, Roberto. La sala de máquinas de la Constitución: dos siglos de Constitucionalismo en América Latina (1810-2010).

Constitucionalismo vs. Democracia. In: ZAMORA, Jorge Luis Fabra; SPECTOR, Ezequiel (Editores). Enciclopedia de Filosofia y Teoria del Derecho. Volume Três. Mexico: Universidad Nacional Autonoma de Mexico, 2015. Disponível em: <http:bliblio.juridicas.unam.mx.libros.libro.htmI.3876>. Acessado em 07 de agosto de 2016.

. El nuevo constitucionalismo latino-americano. Promessas e interrogantes In:

CEPAL - Serie Políticas Sociales, n. 153. Nações Unidas: Santiago del Chile, 2009

Por qué estudiar constitucionalismo popular in América Latina. In: ALTERIO, Ana Micaela; ORTEGA, Roberto Niembro. (Orgs.) Constitucionalismo popular em Latinoamerica. Spanish Edition. México: Biblioteca Jurídica Porrúa, Escuela Libre del Derecho, 2013, Kindle Edition, prologo.

El nuevo constitucionalismo dialógico, frente al sistema de los frenos y contrapesos. Revista Argentina de Teoria Jurídica, vol. 14, diciembre de 2013.

ORTEGA, Roberto Niembro. Qué es el Constitucionalismo popular? Una breve referencia al uso de las fuerzas armadas en México como fuerzas de seguridad. In: ALTERIO, Ana Micaela; ORTEGA, Roberto Niembro. (Orgs.) Constitucionalismo 
Prelúdios de um constitucionalismo popular e latino-americano no Brasil? participação democrática pós-88 e queda do Decreto-lei 8.243/2014

popular em Latinoamerica. Spanish Edition. México: Biblioteca Jurídica Porrúa, Escuela Libre del Derecho, 2013, Kindle Edition, Primeira Parte.

POGREBINSCHI, Thamy. Conferências nacionais e políticas públicas para grupos minoritários. In: AVRITZER, Leonardo, SOUZA, Clóvis Henrique Leite de (Orgs.). Conferências nacionais: atores, dinâmicas participativas e efetividades. Brasília: Ipea, 2013.

. Novo decreto: Não há representação sem participação. Carta Capital, 19/06/2014. Disponível em: <http://www.cartacapital.com.br/politica/novo-decreto-naoha-representacao-sem-participacao-9169.html>. Acessado em 07 de agosto de 2016.

ROCHA, Roberto. A gestão descentralizada e participativa das políticas públicas no Brasil. Revista Pós Ciências Sociais, v. 01, n. 11: São Luis/MA, 2009.

TUSHNET, Mark V. Popular Constitucionalism as political law. Georgetown University Law Center, 2006. Disponível em:

$<$ http://scholarship.law.georgetown.edu/facpub/233/>. Acessado em 07 de agosto de 2016.

UNGER, Roberto Mangabeira. A constituição do experimentalismo democrático. Revista de Direito Administrativo, Rio de Janeiro, v. 257, p. 57-72, maio/ago. 2011.

UNPRIMNY, Rodrigo. Las transformaciones constitucionales recientes en América Latina: tendencias y desafíos. In: GARAVITO, Cesar Rodrigues. El derecho en América Latina: un mapa para el pensamento jurídico del siglo XX. 1 ed. Buenos Aires: Siglo Veintiuno Editores, 2011.

Artigo recebido 20 de julho de 2017 e aceito em 25 de novembro de 2017

\footnotetext{
${ }^{1}$ Essa pergunta é realizada por Roberto Gargarella em diversos textos de sua autoria. Ver, a propósito: In: GARGARELLA, Roberto. La sala de máquinas de la Constitución: dos siglos de Constitucionalismo en América Latina (1810-2010). Buenos Aires: Katz Editores, 2014.

${ }^{2} \mathrm{O}$ constitucionalismo popular, constitucionalismo democrático ou constitucionalismo débil são categorias utilizadas para caracterizar esse debate acerca da necessidade de se resgatar o papel do poder constituinte e da soberania popular, na construção de sentido da democracia e da Constituição. A variação da nomenclatura pode ser justificada pelo modo que importantes autores se apropriam dessa discussão, imprimindo leituras diferenciadas a algumas variáveis dessa
} 
narrativa. A propósito, ver: Robert Post, Reva Siegel, Joel Colón Rios, Roberto Gargarella, Mark Tushnet, dentre outros.

3 Roberto Gargarella define como sala de máquinas da Constituição os dispositivos constitucionais que disciplinam a organização do poder de um Estado. In: GARGARELLA, Roberto. La sala de máquinas de la Constitución: dos siglos de Constitucionalismo en América Latina (1810-2010). Buenos Aires: Katz Editores, 2014

${ }^{4}$ Logicamente que os enxertos constitucionais resultantes destas mudanças sociais ocasionaram profundo impacto sobre o paradigma de "ordem e progresso". Porém, a potencialidade democrática continua limitada e prejudicada, face a organização de poderes profundamente verticalista. In: GARGARELLA, Roberto. Constitucionalismo vs. Democracia. In: ZAMORA, Jorge Luis Fabra; SPECTOR, Ezequiel (Editores). Enciclopedia de Filosofia y Teoria del Derecho. Volume Três. Mexico: Universidad Nacional Autonoma de Mexico, 2015, p. 356-358).

${ }^{5}$ Observa-se, contudo, que boa parte das constituições da região ainda conserva ampla gama de poderes concentrados na figura do presidente, ao modelo clássico estadunidense, fenômeno chamado por Gargarella de hiperpresidencialismo. A propósito, ver: GARGARELLA, Roberto. La sala de máquinas de la Constitución: dos siglos de Constitucionalismo en América Latina (1810-2010). Buenos Aires: Katz Editores, 2014, p. 310 -314).

${ }^{6}$ Roberto Mangabeira Unger chama de experimentalismo democrático sua ideia de construção das instituições, das práticas e das doutrinas de uma democracia de alta energia, capaz de fazer com que as mudanças passem a depender menos das crises. $\mathrm{O}$ interesse maior a que deve servir esta reconstrução é o do avanço rumo a um modelo de desenvolvimento, baseado em ampliação de oportunidades econômicas e educativas. A prática do direito - inclusive do direito constitucional - trocaria a idealização das normas vigentes (o discurso dos princípios e das políticas públicas) pela imaginação das instituições alternativas. Sua compreensão de democracia é de um processo de descoberta e de aprendizagem coletivas. Ao direito, a começar pelo direito constitucional, cabe organizar este processo e tomar como suas as aspirações do projeto democrático. $\mathrm{O}$ aprofundamento do experimentalismo democrático é, ao mesmo tempo, para o direito, assim como para a democracia, método e alvo. In: UNGER, Roberto Mangabeira. A constituição do experimentalismo democrático. Revista de Direito Administrativo, Rio de Janeiro, v. 257, p. 57-72, maio/ago. 2011.

7 Mark Tushnet desenvolve um importante debate sobre essa questão, ao afirmar que o constitucionalismo popular produz direito político, uma vez que o resultado da interação entre as pessoas mobilizadas, representantes políticos e os tribunais oferecem interpretações constitucionais, produzem norma constitucional. Seu traço distintivo dos outros tipos de concepções teóricas do constitucionalismo é que nesta perspectiva popular, os tribunais não possuem prioridade normativa. In: TUSHNET, Mark V. Popular Constitucionalism as political law. Georgetown University Law Center, 2006. Disponível em: $<$ http://scholarship.law.georgetown.edu/facpub/233/>. Acessado em 07 de agosto de 2016.

${ }^{8}$ Os conselhos foram estabelecidos nas esferas federal, estadual e municipal, cobrindo diversas áreas temáticas. Visam incorporar a participação da sociedade no ciclo de políticas públicas e possibilitar formas de controle sobre as ações do Estado. Podem desempenhar, conforme o caso, funções de fiscalização, de mobilização, de deliberação ou de consultoria. A função fiscalizadora dos conselhos pressupõe o acompanhamento e o controle dos atos praticados pelos governantes. A função mobilizadora refere-se ao estímulo à participação popular na gestão pública e às contribuições para a formulação e disseminação de estratégias de informação para a sociedade sobre as políticas públicas. A função deliberativa, por sua vez, refere-se à prerrogativa dos conselhos de decidir sobre as estratégias utilizadas nas políticas públicas de sua competência, enquanto a função consultiva relaciona-se à emissão de opiniões e sugestões sobre assuntos que lhes são correlatos. Já as conferências são formas de participação popular, capazes de discutir R. Fac. Dir. UFG, v. 41, n.2, p. 169-195, maio / ago. 2017

ISSN 0101-7187 
Prelúdios de um constitucionalismo popular e latino-americano no Brasil? participação democrática pós-88 e queda do Decreto-lei 8.243/2014

questões que antecedem o processo de formulação de políticas, colaborando para o processamento da agenda de um setor e permitindo o diálogo entre a sociedade e o Estado. Ganham impulso a partir de 2003, quando houve ampliação desse mecanismo na esfera federal. Seus resultados são heterogêneos, dependendo do setor envolvido. In: FERRAREZI, Elisabete; OLIVEIRA, Clarice G. Reflexões sobre a emergência da participação social na agenda das políticas públicas: desafios à forma de organização burocrática do Estado. Anais do V Congresso de Gestão Pública, CONSAD. Escola de Administração Pública: Brasília, junho de 2012. Disponível em: <http://www.segplan.go.gov.br/post/ver/167051>. Acessado em 07 de agosto de 2016.

9 Informação disponível no relatório de pesquisa do IPEA: <http://www.ipea.gov.br/participacao/images/pdfs/relatoriofinal_perfil_conselhosnacionais.pdf $>$ Acessado em 07 de novembro de 2016.

${ }^{10}$ Art. $4^{\text {o }}$ do Decreto-Lei 8243/2014 - São objetivos da PNPS, entre outros: I - consolidar a participação social como método de governo; II - promover a articulação das instâncias e dos mecanismos de participação social; III - aprimorar a relação do governo federal com a sociedade civil, respeitando a autonomia das partes; IV - promover e consolidar a adoção de mecanismos de participação social nas políticas e programas de governo federal; V - desenvolver mecanismos de participação social nas etapas do ciclo de planejamento e orçamento; VI - incentivar o uso e o desenvolvimento de metodologias que incorporem múltiplas formas de expressão e linguagens de participação social, por meio da internet, com a adoção de tecnologias livres de comunicação e informação, especialmente, softwares e aplicações, tais como códigos fonte livres e auditáveis, ou os disponíveis no Portal do Software Público Brasileiro; VII - desenvolver mecanismos de participação social acessíveis aos grupos sociais historicamente excluídos e aos vulneráveis; VIII - incentivar e promover ações e programas de apoio institucional, formação e qualificação em participação social para agentes públicos e sociedade civil; e IX - incentivar a participação social nos entes federados. Disponível em: <http://www.planalto.gov.br/ccivil_03/_Ato20112014/2014/Decreto/D8243.htm>. Acesso em: 07 de dezembro de 2016.

11 Decreto-Lei 8243/2014, Disponível em: <http://www.planalto.gov.br/ccivil_03/_Ato20112014/2014/Decreto/D8243.htm>. Acesso em: 07 de dezembro de 2016.

12 Dados disponíveis no portal Participa.br. Disponível em: <http://www.participa.br/profile/mobilizapnps>. Acesso em: 07 de dezembro de 2016. 